\title{
Treatment of perianal fistulae with fibrin sealant
}

\author{
Emad M Salah, $M D$
}

\author{
Department of General Surgery, Zagazig University, Egypt.
}

\begin{abstract}
Background: The surgical management of high perianal fistula is associated with the risk of sphincter injury. Injection of fibrin sealant in the fistula tract is a simple procedure in an attempt to avoid more radical surgical intervention .

Objective: The purpose of this study was to evaluate the effects of fibrin sealant in treatment of high perianal fistula.

Method: Between October 2006 to December 2009, only patients with high perianal fistulae were included in this study. Injection of fibrin sealant into the fistulous tract under anesthesia was done. Patients were actively followed up at two weeks, one, two, six months and one year.

Results: The study included a total of 16 patients, 12 males (74.5\%) and 4 females (25.5\%), the age ranging from 32 to 55 years, the mean age 43.2 years. The type of fistulae as delineated by ultrasound were 10 intersphincteric (62.5\%) and 6 transphincteric (37.5\%). The success rate was 50\%, the success rate among intersphincteric type of fistula was $60 \%$ and the transphincteric type was $34 \%$. No complications were reported in our study.

Conclusion: Fibrin sealant injection was a useful treatment alternative in the treatment of perianal fistula. It may potentially preclude more extensive surgery in more than one half of patients. Further study should be designed to define predictors of success for better patient selection.

Key words: Fibrin sealant, treatment, perianal fistula.
\end{abstract}

\section{Introduction:}

Surgical management of complex perianal fistulae is challenging and may be associated with the risk of sphincteric injury. ${ }^{1}$

Complications from the repair of fistulae in ano can be devastating. While it is common practice to treat individuals with intersphincteric or low transsphincteric fistulae with fistulotomy, fecal incontinence in these patients has been reported. Even more common, but often under reported, is permanent flatus incontinence. Another postoperative complication after surgical treatment of anal fistula is recurrence. ${ }^{2,3}$

Fibrin sealant has been used in many surgical conditions. Several trials of using fibrin sealant in the treatment of fistula in ano have been performed. ${ }^{2,3}$ By using fibrin sealant in treating high perianal fistula, patients can avoid the risks of staged seton procedure and the risk of fecal incontinence.
In addition the prolonged discomfort associated with wound dressing after operation can be avoided. ${ }^{2,4}$

Fibrin sealant is a tissue sealant that uses the activation of thrombin to form a fibrin clot, which mechanically seals the fistula tract. The clot undergoes gradual fibrinolysis while promoting tissue healing processes to permanently obliterate the fistula tract. The use of fibrin sealant has recently emerged as a simple and repeatable procedure for the treatment of high perianal fistulae. This procedure, done as a day case surgery, does not interfere or compromise subsequent surgical options. Moreover the prolonged discomfort associated with wound dressing after surgery may be avoided. 3,5-7

The objective of this study was to assess the use of fibrin sealant in the treatment of high perianal fistulae. 


\section{Methods:}

Between October 2006 to December 2009, sixteen patients suffering from high perianal fistulae participated in our study; twelve of them were males $(74.5 \%)$ and four were females $(25.5 \%)$. Their ages ranged from 32 to 55 years, the mean age was 43.2 years.

The inclusion and exclusion criteria are listed in this table.

\begin{tabular}{|l|}
\hline Inclusion criteria: \\
\hline 1- Age: above 18 years of age \\
\hline $\begin{array}{l}\text { 2- High perianal fistula encompassing at least } \\
\text { one third of external anal sphincter muscle }\end{array}$ \\
\hline $\begin{array}{l}\text { 3- Patient understanding the study and signs } \\
\text { an informed consent. }\end{array}$ \\
\hline Exclusion criteria: \\
\hline $\begin{array}{l}\text { 1- Perianal abscess or undrained collection noted } \\
\text { on preoperative clinical assessment. }\end{array}$ \\
\hline $\begin{array}{l}\text { 2- Perianal abscess or undrain collection as assessed } \\
\text { by preoperative imaging studies defined as local } \\
\text { enlargement at least twice the width of the fistula tract }\end{array}$ \\
\hline 3- Body temperature > 38 \\
\hline 4- White blood cell count > 12,000 \\
\hline 5- Known allergy to fibrin sealant \\
\hline \begin{tabular}{l} 
6- Immunodeficiency condition \\
\hline 7- Pregnancy
\end{tabular} \\
\hline
\end{tabular}

\section{Preoperative investigations:}

All patients were preoperatively examined by a surgeon for eligibility to participate in this study. Determination for inclusion was undertaken by clinical examination, endorectal ultrasound and fistulographic examination. Imaging of the fistula tract with ultrasound and fistulography was aimed at detecting any associated cavities and secondary tracts.

\section{Surgical procedure:}

Two days prior to surgery, patients were placed on a liquid diet and cleansing enema was done prior to injection. The procedure took place as a day case surgery under general or spinal anaesthesia with the patient placed in the lithotomy position. The fistula tract was curetted using a blunt curette. Gauze was packed in the rectum of the patient before injection to prevent spillage of fibrin sealant into the rectum or anal canal. A commercially made fibrin sealant was used. Before application, the fibrin sealant was prepared and kept at room temperature, as recommended by the manufacturer. Two components were prepared (the first component: fibrinogen concentrate, human plasma protein fraction with factor XIII activity and aprotinin; the second component: Thrombin and calcium chloride solution). They were then siphoned into two syringes and connected to a dual chamber applicator. The dual-chamber applicator syringe was put inside the fistula tract through the external opening and fibrin sealant was injected until the whole tract was filled with sealant. This normally required a total of $1 \mathrm{ml}$, the patient was then instructed to have a half-hour period of rest to avoid back flow of fibrin sealant and to allow fixation of the fibrin plug. After that the gauze pack was removed and a one week course of oral antibiotics prescribed (cefuroxime $250 \mathrm{mg}$ twice daily and mitronidazol 500mg three times daily). 


\section{Follow-up:}

All patients were actively followed up at two weeks and one, two, six months and one year after the procedure. Each visit included physical examination to assess for recurrence and any adverse effects. Success of the procedure was defined as the clinical absence of any discharge through the external or internal opening per history, clinical examination and transanal ultrasound. Patients with fistula recurrence were offered additional injection of fibrin sealant.

\section{Results:}

Sixteen patients participated in our study, twelve of them males and four females. Their age ranged from 30 years to 55 years, the mean age was 43.2 years. The fistulae types (as delineated by ultrasound) were summarized in Table(1).

Table (1): Fistula type by ultrasound and its success rate.

\begin{tabular}{|l|c|c|}
\hline Fistula type & Number $(\%)$ & Success rate $(\%)$ \\
\hline Intersphincteric & $10(62.5 \%)$ & $6 / 10(60 \%)$ \\
\hline Transphincteric & $6(37.5 \%)$ & $2 / 6(34 \%)$ \\
\hline
\end{tabular}

The results were categorized as failure (persistent discharge) and success (no discharge), on follow up by clinical assessment ( history, physical examination and transanal ultrasound). No patients defaulted follow up at the end of the study period. The results are summarized in Table(2).

Table (2): Age, sex, previous operation, fistula type and clinical results.

\begin{tabular}{|c|c|c|c|c|l|}
\hline No. & Sex & Age & Previous operation & Fistula type & Rresults \\
\hline 1 & Male & 50 & No & Intersphencteric & Success \\
2 & Female & 55 & No & Intersphencteric & Failure \\
3 & Male & 43 & No & Transphincteric & Failure \\
4 & Male & 35 & Yes & Intersphencteric & Success \\
5 & Male & 37 & No & Transphincteric & Failure \\
6 & Female & 32 & No & Intersphencteric & Failure \\
7 & Male & 40 & No & Transphincteric & Failure \\
8 & Male & 48 & No & Intersphencteric & Failure \\
9 & Male & 39 & No & Intersphencteric & Success \\
10 & Male & 53 & No & Intersphencteric & Success \\
11 & Female & 51 & Yes & Transphincteric & Success \\
12 & Male & 42 & No & Transphincteric & Failure \\
13 & Female & 31 & Yes & Intersphencteric & Success \\
14 & Male & 30 & No & Transphincteric & Success \\
15 & Male & 46 & Yes & Intersphencteric & Failure \\
16 & Male & 39 & No & Intersphencteric & Success \\
\hline
\end{tabular}


All patients completed a six month and one year follow up from the last injection of fibrin sealant. The fistula completely healed and remained closed during the follow up period in 8 patients ( $50 \%)$ and in 8 patients $(50 \%)$ a recurrent fistula was detected during the follow up period and the procedure was considered a failure, these patients refused the second injection and chose the surgical treatment. Only one patient did not respond after the first injection, chose a second injection one month after the first injection, and showed no response.

Four of sixteen patients had previous surgical attempts. The success rate for these patients was $50 \%(2 / 4)$.

The success rate with intersphincteric type of fistula was higher $60 \%$ (6/10) compared with the transphincteric $34 \%$ (2/6). All patients tolerated the injection procedure very well. There were no adverse effects.

\section{Discussion:}

Fibrin sealant is a treatment option for anal fistulae and possesses many advantages in the treatment of difficult high fistulae. Fibrin sealant treatment is simple and repeatable, failure does not compromise further treatment option and sphincter function is preserved. ${ }^{9}$

In our study, the procedure was done under general or regional anesthesia in all patients. This agrees with Zmora et al, ${ }^{1}$ Loungnarath et al ${ }^{10}$ and Hammand et al. ${ }^{11}$ But the procedure was performed without general or regional anesthesia by Chan et $\mathrm{al}^{2}$ and Singer and Cintron. ${ }^{12}$

As regards the success rate, in our study 8 patients $(50 \%)$ showed success, this was nearly the same as reported by Fuks et al, ${ }^{13}$ Maralcan et al, ${ }^{14} \mathrm{Zmora}$ et $\mathrm{al}^{1}$ and Jose et $\mathrm{al}^{15}(60 \%$, $62.8 \%, 11 \%$ and $54 \%$ respectively). But Jurczak et al ${ }^{16}$ and Vitton et $\mathrm{al}^{5}$ reported higher success rate $(83.9 \%$ and 81.6 respectively). On the other hand Linsey et al, Loungnarath et al ${ }^{10}$ and Hammand et $\mathrm{al}^{11}$ found lower success rate (30\% 12\% and $10 \%$ respectively). This may be due to the difference in types of fistulae included and the difference in follow up periods.

As regards the adverse effects of fibrin sealant injection, in our study no adverse effects were reported in all patients. This goes hand by hand with, Hammand et $\mathrm{al}^{11}$ and Chan et al. ${ }^{2}$ But Zmora et $\mathrm{al}^{1}$ reported many adverse effects in $47 \%$ of patients, the majority were mild and self limited such as minor pain, pruritus and perianal abscess which needed drainage.

Only one patient in this study selected to undergo repeated injection. The success rate after the second injection was lower than the initial attempt. This pass hand by hand with Zmora et $\mathrm{al}^{1}$ and Chan et al. ${ }^{2}$ But only one patient preferred a second injection in our study and this is not enough to compare with other results. But Roberto et $\mathrm{al}^{3}$ found higher success rate at repeated injection $70 \%$.

In this study intersphincteric type of fistula have better success rate as shown in our results: 6 patients from 10 patients $(60 \%)$ success rate per fistula type. While the transphencteric type of fistula has a lower success rate to the fibrin sealant injection, 2 patients from 6 patients (34\%) showed success rate per fistula type. The possible explanation is that the activity of the sphincter muscle squeezed out the fibrin sealant from the fistula tract. This result is the same as reported by Chan et $\mathrm{al}^{2}$ and Zmora et al. ${ }^{1}$

As regards the successful rate of fibrin sealant injection in patients with recurrent perianal fistula, in our study the success rate was $50 \%$. This is the same as reported by Chan et $\mathrm{al}^{2}{ }^{2}$ But Vitton et al ${ }^{5}$ reported that only $14 \%$ of recurrent fistulae healed.

In conclusion, fibrin sealant injection is a useful treatment alternative in the management of high perianal fistula, it may potentially preclude more extensive surgery in half of the patients. Further study should be designed to define predictors of success for better patient selection.

\section{References:}

1- Zmora O, Neufeld D, Ziv Y, Tulchinsky H, Scott D, Khaikin M, Stepansky A, Rabau M, Koller M: Prospective, multicenter evaluation of highly concentrated fibrin glue in the treatment of complex cryptogenic perianal fistulas. Dis Colon Rectum 2005; 48(12): 2167-2172. 
2- Chan KM, Lau CW, Lai KK, Auyeung MC, Luk HT, Lo KH: Preliminary results of using a commercial fibrin sealant in treatment of fistula-in-ano. Dis Colon Rectum 2006; 49(3): 371-376.

3- Roberto C, Eriberto F, Francesco L, Lorenzo C, Barbara C, Diego M: Fibrin glue in the treatment of anal fistula: A systemic review. Ann Surg Innov Res 2009; 3: 12.

4- Venkatesh KS, Ramanujam P: Fibrin sealant application in the treatment of recurrent anorectal fistulas. Dis Colon Rectum 1999; 42: 1136-1139.

5- Vitton V, Gasmi M, Barthet M, Desjeux A, Orsoni P, Grimaud JC: Long-term healing of Crohns anal fistulas with fibrin glue injection. Aliment Pharmacol Thr 2005; 15; 21(12): 1453-1457.

6- Cintron J R, Park JJ, Orsay CP, Pearl RK, Nelson RL, Abcarian H: Repair of fistulain-ano using fibrin glue. Dis Colon Rectum 1999; 42: 607-613.

7- Hjortrup A, Moesgaard F, Kjaergard J: Fibrin adhesive in the treatment of perineal fistulas. Dis Colon Rectum 1991; 34: $752-$ 754.

8-Lindsey I, Smilgin MM, Cunningham C, Mortensen NJ, George BD: A randomized, controlled trial of fibrin glue vs. conventional treatment for anal fistula. Dis Colon Rectum 2003; 46(8): 1148-1149.

9- Johnson EK, Gaw JU, Armstrong DN: Effecacy of fibrin plug vs. fibrin glue in closure of anorectal fistulas. Dis Colon Rectum 2006; 49(3): 371-376.

10-Loungnarath R, Dietz DW, Muth MG, Birnbaum EH, Kodner IJ, Fleshman JW: Fibrin glue treatment of complex anal fistulas has low success rate. Dis Colon Rectum 2004; 47(4): 432-436.

11-Hammand TM, Grahn MF, Lunniss PJ: Fibrin glue in the management of anal fistulae. Colorectal Dis 2005; 7(5): 528529.

12-Singer M, Cintron J: New techniques in the treatment of common perianal diseases: Stapled hemorrhoidopexy, botulinum toxin, and fibrin sealant. Surg Clin North Am 2006; 86(4): 937-967.

13-Fuks D, Brehant O, Dumont F, Viart L, Manaouil D, Bartoli E, Yzet T, Mauvais F, Regimbeau JM: Tissue adhesive treatment of persistent recto-cutaneous fistula following Hartmann procedure. $J$ Chir (Paris) 2007; 144(1): 35-38.

14-Maralcan G,Baskonus I, Aybasti N, Gokalp A: Fibrin sealant in treatment of fistula-inano. Surg Today 2006; 36(2): 166-170.

15-Jose R, John J, Park C, Orsay R, Russel K, Pearl R, Julia H, Herand A: Repair of fistulas-in-ano using fibrin adhesive. Dis Colon Rectum 2000; 43(7): 1530-1534.

16-Jurczak F, Laridon J Y, Raffaitin P, Pousset JP: Biological fibrin used in anal fistulas: 31 patients. Ann Chir 2004; 129(5): 286289. 